\title{
Amálgama entre o professor inclusivo e o universo da educação física
}

\author{
Calixto Júnior de Souza* \\ Morgana de Fátima Agostini Martins **
}

\section{Resumo}

O objetivo timoneiro deste trabalho é compreender os liames entre a formação de professores e o processo de inclusão, almejando tecer uma gama de elementos que irão contribuir para a compreensão do objeto de estudo buscando responder a problemática do estudo, dos quais muitos deles permanecem conflituosos perante a área de Educação Física não possibilitando a compreensão da simbiose entre o professor inclusivo e o universo da Educação Física. Para tanto, faz se uso de uma pesquisa com um cunho bibliográfico como forma de coletar dados que possam subsidiar o entendimento da análise que será trabalhada neste estudo. Por meio do estudo é possível apontar que a área de Educação Física necessita superar uma série de conflitos que impossibilitam a aproximação com o processo de inclusão, entendendo-se, aqui, como um processo que almeja incluir todos aqueles alunos que sempre foram segregados e marginalizados do âmbito do ensino regular. Contextualizando com a Educação Física tal processo se torna mais sensível considerando que é uma área que sempre se caracterizou por destacar os mais hábeis e mais habilidosos, enquanto os outros eram (são) considerados derrotados não se adaptando aos moldes concebidos pelo esporte de alto-rendimento. Portanto, ao se pensar na formação de professores em Educação Física é preciso considerar todas as nuances que podem levar a exclusão dos alunos com necessidades especiais com o intuito de fortalecer o processo de inclusão com transparência com a diversidade que permeia no âmbito escolar.

Palavras-chave: Formação de professores; Inclusão; Educação Física.

\footnotetext{
* Mestrando em Educação pela Universidade Federal da Grande Dourados. Dourados, Mato Grosso do Sul.

** Professora Doutora da Universidade Federal da Grande Dourados, Faculdade de Ciências Humanas. Dourados, Dourados, Mato Grosso do Sul.
} 


\title{
Amalgam between the inclusive teacher and the universe of physical education
}

\begin{abstract}
The aim of this pilot study is to undestand the connection between teacher training and the inclsion process, aiming to maki a range of elements that will contribute to the undestanding of the object of study seeking to answer the question of the study many of wich remain in the face of conficting Physical Education is not enabled understanding of the symbiosis between the inclusive teacher and the universe of physical education. Therefore, it is using a literature search with a character as a way to collect data that can support the undestanding of the analysus that will be worked in this study. Through the study it is possible to point out that the área of Physical Education needs to overcome a series of conflicts that make it impossible to approach with the inclusion process, it being understood here, as a process that aims to include all those students who were Always segregated and marginalized the contour for regular education and physical education with contextualizing this process becomes more sensitive whereas it is na área that has been characterized by highlighting the most skilled and more skilled, while the others were (are) considered to be defeated not by adaptin to molds designed for high-performance sports. Therefore, whem thinking in teacher education in physical education is necessary to consider all the nuances that can lead to exclusion of students with special needs in order to strengthen the inclusion process with transparency that pervades the diversity in the school.
\end{abstract}

Keywords: Formation of teachers; Inclusion; Physical Education.

\section{Introdução}

Tendo como ponto de partida a ínfima produção de trabalhos relacionados à inclusão no universo da área de Educação Física como aponta Bueno (2008) em um ensaio na qual analisa as produções ligadas à inclusão nos cursos de pós-graduação no país, urge compreender como pode ser articulada a temática inclusão com os fundamentos que norteiam a área de Educação Física, dos quais muitos deles ainda permanecem confusos e carregados de conflitos no âmago dessa área. Com isso, é preciso compreender como pode ser estruturada uma formação de professores que possa revelar a configuração de um professor inclusivo no universo da área 
de Educação Física que possibilite a participação de todos os alunos na sala de aula.

Neste sentido, o objetivo timoneiro deste trabalho é compreender os liames entre a formação de professores em Educação Física e o processo de inclusão de modo a apontar uma gama de elementos que possibilitam delimitar as aproximações entre esses dois contextos, já que a configuração de um professor inclusivo pressupõe a construção de um indivíduo atento com a diversidade e com os processos excludentes no universo educativo.

Este trabalho utiliza-se da pesquisa bibliográfica como suporte para a análise bem como para proporcionar subsídios para a discussão.

Neste contexto, é importante reiterar os propósitos do movimento de inclusão escolar, já que o termo inclusão instiga a configuração de novos rumos e horizontes para a educação e, sobretudo, almeja possibilitar não apenas o acesso, mas também a permanência de todos os excluídos e marginalizados no âmbito do ensino regular, na qual inclui aqueles alunos com deficiência, carentes, hiperativos, obesos, negros, com déficit de aprendizagem, dentre outros.

Como pode ser verificado, há uma gama de pessoas que serão contempladas nesse processo de inclusão, tendo em vista que o movimento de inclusão só se faz sentido quando aborda o lema "escola para todos" de modo que a escola possa tornar-se um espaço que contemple a diversidade e por meio dela possa enriquecer mutuamente o seu processo de ensinoaprendizagem, cuja a aceitação das diferenças é uma válvula propulsora para romper todos os ditames segregadores que persistem e coexistem em nossa educação.

\section{Relação entre o movimento de inclusão e a educação física}

Considerando o contexto histórico, anteriormente ao movimento de inclusão poucos eram os alunos com Necessidades Educacionais Especiais (NEE) no âmbito do ensino regular na qual a maioria dos alunos era relegada ao ensino especial ou a espaços considerados segregadores, isso porque tinha como referência tão somente o aspecto orgânico. Em outras palavras, por focar no aspecto orgânico somente os alunos que possuíam deficiências leves e que não comprometessem o trabalho pedagógico do professor eram os escolhidos para serem incluídos, enquanto os considerados 'outros' faziam parte do grupo direcionado ao ensino especial. Assim, eles eram rotulados 
como incapazes antes mesmo de integrarem no processo de ensino e aprendizagem.

Mediante as contribuições de Santos (2008) no que se refere à trajetória escolar de alunos de classes especiais, é possível constatar que está instalado um senso comum de que os alunos com NEE possuem limitações que não podem ser exploradas no ensino regular, cabendo tão somente se conformarem com um ensino especial, já que as ditas limitações não são compatíveis com o ensino regular. Dessa forma, para continuar a progredir nos estudos os alunos com NEE devem provar que não possuem limitações e se adaptar a esquemática pré-determinada de ensino-aprendizagem delineado pela escola, que não possibilita avanços na forma de conceber um ensino articulado com as necessidades específicas de cada aluno por meio de suas competências. Segundo o estudo do autor supracitado também foi possível averiguar que as classes especiais não conseguem proporcionar um ensino que ajude o aluno a superar as suas dificuldades anteriormente trilhadas no processo de ensino e aprendizagem e, assim, os alunos com NEE ficam estagnados no âmbito do saber e também do conhecer enquanto processo.

Interessante notar que a justificativa para o insucesso na aprendizagem dos alunos sempre recai no aluno e não no processo de ensino, dessa forma há uma 'culpabilização' no aluno deixando de identificar falhas e lacunas no próprio processo de ensino de modo a possibilitar melhorias e superar as limitações. Dessa forma, ressaltando essa 'culpabilização' delegada ao aluno, muitos alunos com NEE são direcionados ao ensino especial sem ao menos terem sido incluídos no ensino regular, denotando a fragilidade da escola em incluir esses alunos no ensino regular, como é de direito dos mesmos.

Relacionando este filtro para ambientes segregados com a área de Educação Física, tal relação se torna um pouco mais agravante, e por que não tendenciosa, isso porque muitas práticas remetem a ressaltar valores que enaltecem a exclusão e a não valorização do outro, das quais muitas delas não são perceptíveis à sensibilidade do. Tal realidade é mais difícil no tocante ao lidar e ao ensinar quando abordamos aquelas pessoas que possuem alguma deficiência, em que exigirá uma atenção redobrada do professorado, pois exige que seja (re) pensada a realização da prática perpassando pela estruturação do planejamento do professor, cabendo a ele realizar as adequações cabíveis e pertinentes para atender as individualidades do alunado mediante as necessidades e potencialidades de cada aluno. 


\section{O pano de fundo do ato de adaptar na educação física}

No final do século XIX para o início do século XX, ambas as modalidades esportivas foram sistematizadas por um movimento de 'esportivindualismo', por meio de uma gama de regras, gestos, esquemas, estilos e normas socioculturais que materializavam um novo olhar de encarar o que era jogado de forma lúdica e integrador-formadora. Com isso, o jogo passava a ser rotulado como esporte, com uma base de alto rendimento, sob um aspecto de competição e submissão do jogador a uma lógica neoliberal de conceber o capital intelectual acumulado enquanto legado de subordinação cultural de um egocentrismo em detrimento de um humanismo pautado em posturas inclusivas de encarar o Outro no processo de aprendizagem.

Soares (2007) esclarece pontualmente como decorreu a materialização dessa sistematização de regras e modelos prontos e acabados na área de Educação Física. Clarifica que tal perspectiva de homem a ser moldado para a produção foi fruto de uma intencionalidade com raízes européias, especificamente França e Inglaterra, que minuciosamente estudaram as possibilidades de potencializar o capital material por meio de um esquema de disciplinamento e regramento de valores e interesses materiais e, sobretudo, simbólicos. Tal perspectiva resulta em multiplicar escolas européias que aderiram a essa lógica do sistema neoliberal, pois para conseguir 'sobreviver' ao novo modelo de produção e reprodução do capital (material), fez-se necessário se adequar aos campos institucionalmente dominantes de influências intelectuais para prover o avanço da sociedade de cada país e, não obstante a lógica velada de relações de poder, também o avanço da humanidade, contudo nem sempre um avanço é sinônimo de progresso, pois pode significar um regresso para muitos e o dever de servir para poucos.

No tocante às adaptações que podem ser instrumentalizadas nas práticas do professorado enquanto intervenção, é preciso diferenciar duas formas: a imediatista e a crítica-conscientizadora.

Uma adaptação imediatista é aquela em que o professor realiza de forma instintiva e muito ligada ao momento da efetuação da atividade, não considerando a individualidade do aluno e muito menos quais as situações que podem ser positivas para a inclusão do aluno explorando as suas potencialidades e competências. Factualmente tal adaptação poderá levar a vários momentos de exclusão pelo desconhecimento e descomprometimento com a inclusão enquanto processo de pleno ensino e profícua aprendizagem. 
Por outro lado, uma adaptação crítica-conscientizadora é aquela na qual o professor tem conhecimento de quais potencialidades que podem ser exploradas do aluno no momento da inclusão, e isso perpassa pela estruturação do planejamento do professor envolvendo ações que possibilitem um espaço fecundo para trabalhar o respeito ao outro, o trabalho mútuo e também o espírito de coletividade. É importante destacar que a concretização do segundo modelo de adaptação tem uma exigência maior do professor, pois a atitude de consciência exige uma experiência do professor bem como habilidades no trato do conhecimento de modo a (re) pensar novas formas de incluir todos os alunos, tanto os alunos com e sem deficiência.

De acordo com Carmo (2002), ao se pensar na adaptação na sala de aula pode-se estabelecer uma contradição na prática, isso porque o professor utiliza do recurso da adaptação para aplicar os conhecimentos das diferentes modalidades esportivas (basquete, futebol, voleibol, handebol, natação, dentre outras), adaptando os fundamentos às regras e quando se depara com alguma situação-problema ele executa novas mudanças sem sistematização e sem abarcar as necessidades potenciais dos alunos.

Carmo (2002) também critica com veemência os professores que consideram a adaptação como um feito grandioso nas aulas de Educação Física afirmando que esse recurso de ensino tem servido para acentuar a igualdade universal entre os homens sem conseguir explicitar os princípios da diferença e da desigualdade.

A partir do momento que o professor utiliza-se da adaptação imediatista nas suas aulas, ele estará agindo de forma a encarar a sua prática pedagógica de uma maneira não-planejada. Tentando adaptar essa prática ao aluno com NEE, o professor assume a posição passiva e imediatista de não pensar de modo concreto como poderia desenvolver sua aula de forma a abranger todos os alunos. Portanto, com essa adaptação o professor deve construir uma prática pedagógica sem se focar nas limitações que os alunos NEE possuem, e sim nas potencialidades que eles poderão alcançar.

Com esse pensamento a intenção não é condenar os professores que efetuam as adaptações em suas aulas, e sim ampliar o olhar limitado que eles têm em suas práticas pedagógicas. Nesse sentido, o argumento da adaptação imediatista pode levar a um retrocesso histórico no que tange a retornar às práticas excludentes a partir do momento que retoma a realização das atividades para as classes especiais ou até mesmo para o ensino especial. Dessa forma, só será incluído na escola aquele aluno que possuir condições orgânicas para tal, ou seja, se o aluno não puder se adaptar as aulas ou a própria escola ele acaba sendo descartado das mesmas. 
Há de se destacar o crescimento da linha crítica da EF no que se refere a desmontar os ditames alienadores do esporte de alto rendimento que, infelizmente, ainda persistem nas práticas pedagógicas do professorado. Tal pensamento crítico denota-se em tornar as práticas aligeiradas, equivocadas e imediatistas com um teor consciente e construtivo de conceber a prática pedagógica no sentido de possibilitar uma reconstrução da própria prática bem como uma nova significação dos valores atribuídos à essa prática.

Nesse sentido, podemos destacar a linha crítica alicerçada nos meados da década de 80 que construiu um novo olhar diante da área de EF. Para tanto, foi preciso desvincular a herança de áreas conservadores e com certo teor de dominação de conhecimento, essencialmente relacionados às ciências da saúde enquanto mantedora de práticas reprodutoras do alto rendimento assim como urge disseminar a performance a qualquer custo. Portanto, essa linha pretende desmitificar a positividade do esporte de alto rendimento por meio de práticas calcadas em teorias críticas que almejam construir a Pedagogia do/pelo Esporte.

Sob a perspectiva da Pedagogia do/pelo Esporte, a área de EF avançou no sentido de torna-se um espaço para construir jogos coletivos, digamos, com formatações que almejem abarcar uma coletividade, isso porque a dinâmica do jogo pressupõe a inclusão daqueles alunos que sempre foram segregados por estereótipos, especificamente os alunos com NEE.

\section{Em busca de um professor inclusivo: a caminhada do professor de educação física}

Reconhecendo que a intervenção do professor frente à inclusão escolar é uma condição de extrema importância para que o processo de inclusão se efetive com qualidade e com um teor de concretude, faz-se necessário desvendar a identidade do professor inclusivo no universo da Educação Física, já que esse processo vem a instigar o professor no tocante a sua forma ontológica de planejar as aulas e lidar com o saber trazido pelos alunos. Mantoan (2003) reconhece que tais mudanças pode aterrorizar alguns professores:

A maioria dos professores tem uma visão funcional do ensino e tudo o que ameaça romper o esquema de trabalho prático que aprenderam a aplicar em suas salas de aula é inicialmente rejeitado. Reconhecemos que inovações educacionais como a inclusão abalam a identidade profissional e o lugar conquistado pelos professores em uma dada estrutura ou sistema de ensino, 
atentando contra a experiência, os conhecimentos e o esforço que fizeram para adquiri-los. (MANTOAN, 2003, p. 76)

Ainda sobre a formação de professores com um perfil inclusivo Mendes (2008) destaca a importância da formação de um professor com um perfil inclusivo que possa estimular propostas de intervenção precoce no âmbito da prática pedagógica como forma de enriquecer o processo de inclusão e intensificar atividades fecundas para articular a diversidade. Neste sentido, com o intuito de incluir os alunos com NEE no âmbito do ensino regular, faz-se necessário haver serviços que possam capacitar tanto o professores em serviço como os futuros professores de modo que seja instalada uma cultura de valorização da diversidade e com transparência com o processo de inclusão, e isso perpassa pela estruturação de uma formação inicial e uma formação continuada pautadas em subsídios teórico-metodológicos que instigue a valorização da diversidade e a luta pela inclusão, ao mesmo tempo em que reluta pela exclusão.

$\mathrm{Na}$ atualidade o ensino deve ser encarado de modo simbiótico em que possa haver uma simbiose entre a educação comum e a educação especial de modo que ambas possam enriquecer e levantar a bandeira do processo de inclusão. Para tanto, é importante que também haja a simbiose entre o professor generalista com o professor especializado na qual tal simbiose resulta na contribuição conjunta das carências no campo do saber/ ensinar de cada um, isto é, o professor generalista possa se enriquecer com conhecimentos ligados às diversas deficiências e dificuldades de aprendizagem, ao passo que o professor especializado possa se enriquecer com conhecimentos ligados à prática pedagógica e a forma de conceber o ensino em uma classe comum.

Mendes (2008) denomina esta simbiose como ensino colaborativo ou co-ensino que "é um modelo de prestação de serviço de educação especial no qual um educador comum e um educador especializado dividem a responsabilidade de planejar, instruir, e avaliar a instrução a um grupo heterogêneo de estudantes (2010, p 107).

Considerando o importante papel simbiótico entre ambos os professores supracitados, Rodrigues (2010) aborda o conceito de tutoria que vem a complementar o entendimento da importância de vivenciar e concretizar esta relação no universo da Educação Física. Este autor contextualiza o conceito de tutoria em Educação Física para escolas especiais que apresentam uma gama de alunos com NEE justificando, assim, a presença desse conceito em todas as relações que envolvem o ensino de Educação Física, no entanto a concretização desse conceito também pode 
fazer parte de outros ambientes de ensino que apresentam alunos com NEE como, por exemplo, o ensino regular. O conceito de tutoria se caracteriza pela colaboração conjunta de dois ou mais profissionais ou também do aluno mais habilidoso com menos habilidoso, na qual tal colaboração contribui para ampliar as potencialidades individuais e também para favorecer a transmissão de conhecimento.

No tocante a tutoria entre aluno com aluno, Nabeiro (2010) contribui para entender a relevância desta relação na assimilação do conhecimento de Educação Física. Esta tutoria se caracteriza pela presença de um aluno sem deficiência com um aluno com deficiência na qual o primeiro passa por um treinamento para entender melhor como é a deficiência do segundo, e por meio disso possam estabelecer uma ponte do conhecimento em que tanto o tutor como o tutelado ganham com tal relação e, portanto, este meio constitui como uma estratégia de ensino que pode ser utilizada pelo professorado para aumentar a participação do alunado nas aulas de Educação Física. Importante destacar que nesta relação possa haver um rodízio entre os vários colegas da sala de modo que todos possam contribuir com o processo de inclusão do colega deficiente.

Tendo como norte o acompanhamento do ensino dos alunos com NEE no contexto do ensino regular, frequentemente esses alunos necessitam de apoio de um profissional especialista que possa acompanhálos na evolução de suas potencialidades individuais, dos quais podemos citar: psicólogos, fonoaudiólogos, terapeutas ocupacionais, fisioterapeutas, assistentes sociais, dentre outros. Para tal apoio Mendes (2008) denomina como consultoria colaborativa, cuja finalidade é encaminhar os profissionais especialistas para dentro da escola com o intuito de auxiliarem o professorado a lidar com as necessidades especiais de modo a permitir a evolução da aprendizagem desses alunos por meio de competências. Dessa forma, tanto o professor como o profissional assumem um papel de liderança diante do processo de ensino-aprendizagem com a finalidade de criarem uma prática pedagógica verdadeiramente articulada com o processo de inclusão, com vistas a possibilitar a construção de uma escola inclusiva.

Não obstante a consultoria colaborativa, o grande desafio da inclusão escolar é possibilitar a articulação entre os dois modelos estudados, o ensino colaborativo e a consultoria colaborativa, de modo a criar um modelo tri-colaborativo em que possa ter a colaboração entre os três profissionais: o professor generalista/regular, o professor especializado e o profissional especializado. Com isso, o processo de inclusão dará um grande passo para a efetivação de estratégias que possam auxiliar os ANEE's no âmago do ensino regular bem como enriquecer o trabalho interdisciplinar na qual cada profissional poderá contribuir com conhecimentos pertinentes de sua área.

Revista Educação Especial | v. 26 | n. 46 | p. 277-292 | maio/ago. 2013 


\section{A educação física como colossal área para abordar a temática de inclusão}

Resgatando um pouco o histórico de atuação na área de Educação Física verifica-se um passado que valorizou a aptidão física em que o indivíduo era estereotipado e, portanto, excluído antes mesmo de engajar no processo de ensino-aprendizagem. Carmo (1987), em "Educação Física: uma desordem para manter a ordem", critica o mundo da Educação Física que encaminha para uma óptica aderente ao alto-rendimento, isso porque neste denota-se uma concentração exagerada dos aspectos técnicos, fisiológicos e neurológicos, em que a perfeição é exaltada ao máximo. Em decorrência disso o professor de Educação Física reproduz esses aspectos e também acaba transformando seu ambiente de trabalho em um verdadeiro espelho dos modos de reprodução capitalista e, assim, há uma crucial seleção natural dos indivíduos e um alto índice de exclusão. Nem o professor, nem o médico buscam saber os motivos da inaptidão física, eles preocupam apenas em fugir desta situação e baseiam-se em um falso caráter preventivo: o corpo.

Ressaltando a predominância de fundamentos e princípios de cunho biológico na suposta melhoria dos aspectos atinentes à inclusão dos alunos com NEE no âmago escolar, faz-se necessário repensar sobre as posturas assumidas pelo esporte de alto rendimento para esse âmbito de formação de sujeitos, cabendo estudar e pesar quais são as prioridades que estão sendo trabalhas para atender esses alunos nas aulas de Educação Física e áreas afins.

Coadunando com esse pensamento excludente do universo da Educação Física, Castro (2008) denuncia um modelo médico que tinha um caráter altamente categórico procurando classificar os sujeitos mediante as suas limitações. Para tanto, esse autor relaciona o modelo médico com a disciplina de Educação Física Adaptada. O modelo médico se caracteriza pela articulação dos preceitos médicos nas profissões associadas à assistência, intervenção e a saúde em geral, contendo duas dimensões: a normalidade que está relacionada com ausência de doenças (normalidade $\mathrm{x}$ anormalidade) e patologia que se refere a alterações no organismo decorrentes de doenças. Nesse modelo, os médicos eram (são) os mediadores do conhecimento na qual eles utilizavam de uma abordagem categórica agrupando os indivíduos em categorias em relação a uma patologia em comum.

Já em 1970 surge um modelo para contrapor a esse modelo médico, conhecido como educacional e tem como princípio exaltar as potencialidades do aluno ao invés de priorizar o processo de inclusão na deficiência ou defeito. Diferentemente do modelo médico que tem a deficiência como defeito 
além de ser uma terminologia altamente negativa, no modelo educacional a deficiência é considera como potencial diferencial cujo sujeito é visto como diferente bem como valorizada as suas singularidades (CASTRO, 2008).

$\mathrm{Na}$ atualidade a disciplina e/ou sub-área de Educação Física Adaptada (EFA) tem se tornado uma importante mediadora para o processo de inclusão no universo de Educação Física, cujo objetivo da EFAé possibilitar a difusão de fundamentos teórico-práticos dos vários conhecimentos que compõem a área de Educação Física desde a saúde até a escola, de modo a possibilitar informações de indivíduos que serão incluídos em programas educacionais e de reabilitação em ambientes com a menor restrição possível, preferencialmente no sistema de ensino regular. Neste contexto, se na formação inicial e continuada o professor não teve nenhuma disciplina relacionada com a inclusão como, por exemplo, a Educação Física Especial ou Educação Física Adaptada, isso irá acentuar o desmantelamento de práticas inclusivas em suas aulas e, portanto, tais práticas não almejarão incluir os alunos com NEE no âmago da prática pedagógica, relegando-os a ficar na margem do processo de ensino-aprendizagem.

Nesse sentido, Michels (2005) contribuiu para desconstruir o pensamento predominantemente influente do modelo médico-psicológico a partir do momento que encontra fragilidades no trato positivo de tratar os alunos com NEE, isso porque este trato preocupa-se, em sua maioria, em tão somente avaliar, medir, quantificar e comparar.

Para elucidar a articulação da disciplina EFA no universo da Educação Física, Castro (2008) contribui no sentido de apontar várias ferramentas e temáticas que podem ser trabalhadas na Educação Física com vistas a possibilitar vivências inclusivas bem como atitudes que levem a superação das limitações do alunado. As ferramentas mais populares da EFA são: $1^{\circ}$ ) Atividades desenvolvimentistas; $2^{\circ}$ ) Recreação; $3^{\circ}$ ) Esporte; $4^{\circ}$ ) Dança; $5^{\circ}$ ) Atividades aquáticas; $6^{\circ}$ ) Condicionamento Físico.

No tocante à terceira ferramenta que é o esporte, faz-se necessário compreender como a competição pode ser articulada no âmago das práticas esportivas.

De acordo com Maturana (2002) nenhuma competição é sadia, pois a dinâmica desta competição leva o indivíduo a negar o outro na qual a emoção neste contexto acaba sendo comprometida, principalmente para quem sai derrotado. Já que nas modalidades esportivas apenas há um vencedor e este é o detentor da vitória enquanto o outro, o derrotado, é obrigado a se conformar com a derrota que, muitas vezes, é o passaporte 
para a insatisfação perante o esporte. Ainda mais que, em muitas situações, os alunos com NEE só têm a oportunidade de vivenciar o esporte de altorendimento durante a realização dos Jogos Escolares, tornando-se uma forma velada de incluir esses alunos perante o esporte da escola, pois por se não se adequarem as exigências pré-determinadas da dinamicidade de cada modalidade, eles acabam sendo excluídos das aulas com os demais alunos.

Aos olhos do senso comum, o esporte de alto rendimento tenta persuadir o indivíduo a considerar a competição como algo natural do ser humano de forma que por meio dela é possível criar talentos para representar a patriota população brasileira, seja no âmbito de desporto e do paradesporto. Além disso, a mídia vem a dar suporte para este discurso de competição do esporte de alto rendimento procurando registrar milimetricamente os recordes e vitórias, enquanto a derrota é encarada como fracasso e não como uma lição de vida na parte mais íntima do plano emocional.

Nessa instância, será que podemos negar a competição já que para Maturana (2002) ela não é sadia?

Castellani Filho (1998) delineia um pensamento interessante sobre a competição. Segundo ele o aspecto competitivo não deve ser negado e nem alienado, e sim servir de eixo articulador do processo de tematização dos elementos da cultura corporal pela Educação Física, tendo outro olhar competitivo dos realizados em ambientes fora da escola e imbuídos de um teor capitalista. Para tanto, é preciso esboçar um esporte da escola e não na escola, já que este último é caracterizado pelos moldes do esporte de alto rendimento cabendo a área de Educação Física apenas reproduzi-los de forma alienada. Dessa forma, faz-se necessário aprofundar no entendimento da cultura corporal como recurso humano, material e gerencial por parte do professorado. Com isso, espera-se o aluno vivenciar as diferentes expressões corporais como forma de linguagem corporal, tendo a sua maior representatividade nos jogos lúdicos e nas brincadeiras, assimilando os valores competitivos de modo crítico-conscientizador pode-se se pensar na apropriação dos jogos e brincadeiras adaptados ao esporte de altorendimento almejando a cooperação, o respeito ao próximo e, acima de tudo, a constituição do espírito de inclusão por meio do jogo esportivizado.

O jogo que consistia em regras acordadas por equipes ou povos que decidiam o melhor esquema de regras a proporcionar uma maior inclusão de todos mediante a prática do jogo. Agora, o jogo consiste em regras prémoldadas e fundamentadas em áreas do saber que intervêm no sentido de impor biologização da prática por meio de uma teoria pautada em um modelo 
médico-psicológico, embora prática e teoria sejam indissociáveis, elas são, contudo, pautadas em um cunho de homem e corpo 'ideais' (MICHELS, 2005).

Embora ressaltar o culto a vertente dos jogos/brincadeiras seja um ótimo caminho para superar alguns enlaces segregativos que reina no âmbito escolar, essencialmente nas aulas de Educação Física, sem dúvida o grande desafio do professor de Educação Física é articular os outros conteúdos pertencentes à cultura corporal como, por exemplo, o esporte, de forma que a competição, a seletividade e o rendimento possam ser encarados a partir de um cunho pedagógico, em detrimento de um cunho espelhado no sistema esportivo imbuídos de valores do sistema capitalista hegemonicamente perpetuado em nossa sociedade.

\section{Considerações finais}

Assim, pode-se afirmar que a construção de um professor inclusivo na área de Educação Física não é uma tarefa muito fácil, pois está intrinsecamente ligada a vários pressupostos que instigam a busca pela mudança e a aceitação do novo como algo possível e delineado por meio da busca pelas potencialidades individuais do alunado. Nesse sentido, o professor inclusivo terá que estar atento com práticas que estimulem vivências inclusivas e, portanto, não exaltando os valores do alto rendimento que enaltecem a exclusão na qual apenas os mais hábeis são vangloriados.

Tal reflexão perpassa pela estruturação de uma adaptação críticaconscientizadora que possibilite o professor inclusivo (re) pensar sua prática pedagógica em conformidade com valores inclusivos bem como refletir sobre quais vivências podem desencadear um retrocesso para o processo de inclusão, sobretudo escolar, com isso ressalta-se a presença de um planejamento pautado na diversidade.

Acima de tudo, a tendência na contemporaneidade para acentuar o papel do professor inclusivo é incluir propostas que valorizem o trabalho colaborativo possibilitando a simbiose de vários profissionais com um único propósito: a união de esforços para fortalecer o processo de inclusão em conformidade com a diversidade presente no meio educativo. Dessa forma, ao professor inclusivo de Educação Física é importante que estabeleça relações interdisciplinares com outros professores e também outros profissionais que podem contribuir para a concretização do processo de inclusão. Além disso, já que a disciplina Educação Física Adaptada é a principal mediadora do processo de inclusão na área de Educação Física, faz-se necessário articulá-la com todo o complexo curricular da área de Educação Física, 
almejando um trabalho coletivo e pautado na missão de favorecer teóricometodologicamente conhecimentos ligados à inclusão cujo alvo perpassa pela estruturação de um trabalho colaborativo entre os professores das diversas disciplinas, essencialmente aquelas com um cunho prático.

\section{Referências}

BUENO, J. G. S. A produção acadêmica sobre inclusão escolar e educação inclusiva. In: MENDES, E. G; ALMEIDA, M. A.; HAYASHI, M. C. P. I. (Orgs.). Temas em educação especial: conhecimentos para fundamentar a prática. Araraquara: Junqueira \& Marin, 2008. p. 31- 47.

CASTELLANI FILHO, L. Política educacional e Educação Física. 1. ed. Campinas: Autores Associados, 1998.

CARMO, A. A. Aspectos históricos e filosóficos da deficiência. In: Caderno texto de capacitação de professores multiplicadores em educação física adaptada/ Secretaria de Educação Especial. Brasília: MEC; SEESP, p. 1015, 2002.

A. A. . Educação Física: uma desordem para manter a ordem. In: Vitor Marinho. (Org.). Fundamentos pedagógicos: Educação Física. Rio de Janeiro: Grafica Barbero, 1987, v. 1, p. 41-47.

CASTRO, E. M. Uma proposta para a organização curricular da Educação Física Adaptada nos cursos de Educação Física. In: MENDES, E. G; ALMEIDA, M. A.; HAYASHI, M. C. P. I. (Orgs.). Temas em educação especial: conhecimentos para fundamentar a prática. Araraquara: Junqueira \& Marin Editores, 2008. p. 257- 271.

MANTOAN, M. T. E. Inclusão escolar: o que é? Por quê? Como fazer? São Paulo: Moderna, 2003. (Coleção cotidiano escolar)

MATURANA, H. R. Emoções e linguagem na educação e na política. Belo Horizonte: UFMG, 2002.

MENDES, E. G. Caminhos da pesquisa sobre formação de professores para a inclusão escolar. In: MENDES, E. G; ALMEIDA, M. A.; HAYASHI, M. C. P. I. (Orgs.). Temas em educação especial: conhecimentos para fundamentar a prática. Araraquara: Junqueira \& Marin, 2008. p. 92- 122. 
MICHELS, M. H. Paradoxos da formação de professores para a Educação Especial: o currículo como reiteração do modelo médico-psicológico. 2005. Disponível em: <http://www.scielo.br/scielo.php?script=sci_arttext\&pid =S1413-65382005000200007> Acesso em: 19 nov. 2012.

NABEIRO. M. O colega tutor nas aulas de Educação Física inclusiva. In: MENDES, E. G.; ALMEIDA, M. A. (Orgs.). Das margens ao centro: perspectivas para as políticas e práticas educacionais no contexto da educação especial inclusiva. Araraquara: Junqueira \& Marin, 2010. p. 401406.

RODRIGUES, J. L. A tutoria em Educação Física em Escola Especial com perspectiva inclusiva. In: MENDES, E. G.; ALMEIDA, M. A. (Orgs.). Das margens ao centro: perspectivas para as políticas e práticas educacionais no contexto da educação especial inclusiva. Araraquara: Junqueira \& Marin, 2010. p. 393- 400.

SANTOS, R. A. Processos de escolarização e deficiência: trajetórias escolares singulares de ex-alunos de classe especial para deficientes mentais. In: BUENO, J. G. S.; MENDES, G. M. L.; SANTOS, R. A (Orgs.). Deficiência e escolarização: novas perspectivas de análise. Araraquara: Junqueira \& Marin, 2008. p. 415-465.

SOARES, C. Educação Física: raízes européias e Brasil. 4 ed. Campinas: Autores Associados, 2007. (Coleção Educação contemporânea).

\section{Correspondência}

Calixto Júnior de Souza - Rua Pedro Roriz, n. 1530, Vila América, Inhumas, Goiás.

E-mail: calixtojr_ufg@yahoo.com.br-morganamartins@ufgd.edu.br

Recebido em 12 de janeiro de 2012

Aprovado em 13 de fevereiro de 2013 
